\title{
Co-creating Personalised Experiences in the Context of the Personalisation-Privacy Paradox
}

\author{
Katerina Volchek ${ }^{1(\bowtie)}$, Joanne $\mathrm{Yu}^{2}$, Barbara Neuhofer ${ }^{2}$, \\ Roman Egger ${ }^{2}$, and Mattia Rainoldi ${ }^{2}$ \\ ${ }^{1}$ Deggendorf Institute of Technology, Pfarrkirchen, Germany \\ katerina.volchek@th-deg.de \\ ${ }^{2}$ Salzburg University of Applied Sciences, Puch bei Hallein, Austria
}

\begin{abstract}
The personalisation-privacy paradox demonstrates a two-fold effect of tourists' awareness about personalisation on their experience. Compulsory personal data agreements under the GDPR and similar legislation acts raise tourists' concerns regarding privacy and security. The role of tourist awareness about the value of data-driven personalisation in their co-creation behaviour remains underexplored. This paper applies an exploratory experiment methodology to identify the effects of information about personalisation on tourists' experience with travel information websites. It triangulates the data from eyetracking and self-report techniques, to compare the co-creating behaviour of respondents who have or have not been informed about the value of personalisation. The study demonstrates the presence of a personalisation-privacy paradox. It further reveals that awareness about data-driven personalisation motivates tourists to reinforce value co-creation by ensuring the accuracy of information filtering. The study advances our understanding of tourist digital behaviour and provides insights for the design of personalised information services.
\end{abstract}

Keywords: Personalisation $\cdot$ Privacy $\cdot$ Security $\cdot$ Value reinforcement $\cdot$ Value $\cdot$ Awareness $\cdot$ Experiment $\cdot$ Eye-tracking

\section{Introduction}

The personalisation-privacy paradox is one of the most controversial phenomena in data-driven services. The proliferation of smart technologies [1] combined with the increasing availability of personalisation capabilities offers the prospects of enhanced tourist experiences and induces tourists to prefer personalised websites to nonpersonalised ones [2]. Yet, personalisation technology based on personal data raises a multitude of concerns regarding tourists' privacy and security. Tourists behaviour changes over time and information plays a key role in triggering such change [3]. Legal regulations, such as the General Data Protections Regulation (GDPR), and widely discussed data breaches and misuses by Cambridge Analytica, Cathey Pacific, Marriott and other tech-savvy companies, have in fact exposed the threats of privacy intrusion and frauds, which data-driven personalisation can pose [4]. Given that personalisation 
is named among the key success factors for tourism businesses, practical solutions are required to ensure positive tourists experiences [5]. However, the effect of information about data-driven personalisation on tourist experiences remains underexplored.

This study aims to explore possible effects of tourist awareness of the value that data-driven personalisation offers on their experience with travel information websites. It conceptualises the value of personalisation in enhancing tourist interactions with extensive travel information. The study applies an experimental research design and triangulates the findings of eye-tracking and self-report data to identify changes in tourist value co-creation behaviour under the influence of personalisation information. The findings provide novel insights on tourist interactions with personalised websites, demonstrating earlier unobserved value reinforcement behaviour in the context of the personalisation-privacy paradox. The study contributes to the consumer behaviour and service management domains and creates the background to improve the tourist user experience (UX).

\section{Research Background}

\subsection{Personalised UX}

Personalisation is generally defined as an adaptation of a service in a way that is relevant to satisfy individual tourist needs. Initially, it was possible only by learning preferences, explicitly articulated by tourists themselves [6]. The proliferation of digital tracking technologies and, recently, smart devices, together with the increased storage and computational capacity of computers, enabled the implicit collection of tourist context data and its interpretation in order to recognise tourist needs and preferences [7]. While data-driven personalisation has not yet reached its full potential [8], it is believed to be among the determinants of advanced tourist experiences [9].

This paper explores tourists' experiences with implicit data-driven personalisation. A personalised travel information website tracks tourist personal data and applies it to recognise the tourist's needs and preferences in a specific context. Such preferences are used to filter information that is irrelevant for the tourist, and to deliver a short list of relevant travel services that can satisfy the tourist's expectations [10]. The scope of travel information is exponentially increasing, affecting tourist interactions with travel information websites [11]. Interestingly, the presence of highly diversified travel services increases the time required to select a relevant option. Simultaneously, the extensive exposure to information causes a high cognitive and emotional load, associated with decision-making [12]. A short list of relevant travel services is a proven tool to make tourist interactions with information websites more time-efficient, easier and less confusing, while supporting travel satisfaction. Therefore, personalisation capabilities embedded in travel websites are becoming increasingly important to deliver advanced experiences [13]. 


\subsection{Value Co-creation in Experiences}

Advanced tourist experiences are the result of collaborative resource integration [14]. From the customer side, such resources may include but may not be limited to time, money, cognitive or emotional efforts, reviews, opinions, and personal data. According to the Service-Dominant Logic (SDL) paradigm, resource integration may result either in a positive or a negative outcome, co-creating or co-destructing value in interactions. The outcome depends on the relevance of the resources applied to realise value [15]. Importantly, resource integration is a voluntary process. Not only the customer experience itself, but a tourist's initial decision to participate in it depends on the understanding of the resource integration capability in order to attain value.

Value co-creation is an individual and highly subjective activity, constructed by available information about the tourist's internal and external environment [3]. Exhaustive understanding of value co-creation enables actors to participate in resource integration by determining the resources and ways of their integration. Specifically, actors will likely be willing to contribute their resources and comply with the proposed practices of value co-creation in case they share a congruent understanding about the purpose of the resource integration and its relevance for value co-creation. A lack of understanding of value co-creation may prevent tourists from relevant resource integration, co-destructing value for themselves and for other actors [16]. Therefore, information is among the key resources that can change actors' co-creation behaviour and the value that can be obtained from it [15].

\subsection{Awareness as a Factor of Change in Personalised Experiences}

Tourists are becoming increasingly aware of the potential that data-driven technologies offer [17]. At the same time, the proliferation of personalised services raises tourists' expectations towards the value proposition [18]. Following the GDPR and similar legislation, all data-driven websites have to inform users about applied data [19], thereby, affecting their perceptions of the websites' dependability. Explicit information about the data being collected can raise tourist's levels of trust in personalised service providers, increasing their willingness to share personal data and use the service [2]. However, awareness about possible threats to the individual privacy and security may lead tourists to refuse engaging with travel information websites equipped with personalisation technology [20], and favour the use of not personalised information websites. However, tourists remain largely unaware about personalisation technology being applied by specific travel information websites [21]. This may prevent them from taking full advantage of shortened lists of relevant services, offered by personalisation. However, the effects of information about the value of data-driven personalisation on the tourist value co-creation behaviour and their experience with travel information websites, including their perceptions on efficiency, perspicuity and dependability, remains underexplored. 


\section{Methodology}

The study aimed to explore the potential effects of tourist awareness of the value that data-driven personalisation offer on their interactions with travel information websites. It adopted an exploratory experiment research design, in which the treatment group (TG) was informed about the value of personalisation, while the control group (CG) remained unaware about it. The study searched for differences in behaviour patterns between these two groups of participants.

To perform the experiment, a fictional realistically looking website for attraction booking was created. It contained three main pages. To trigger privacy concerns, the personal data agreement page included the description of data, similar to those, tracked by Booking.com: information search history, online search behaviour, device location, language preferences, device and app details, settings and customer data from them, including payment methods and currency preferences. Second, the page with the list of attractions included a preview of travel destinations and filtering options. Third, a range of pages with the description of each attraction was added to make a website to look realistic. The treatment group was exposed to the additional page with the explicit explanation of the purpose of personal data tracking and the benefit obtainable through the application of the personalisation services before the start of interactions with other web pages. Both groups were exposed to the same content without the use of any personalisation strategy.

To enable a comparison between the two groups, the experiment aimed at a minimum of 30 valid cases. A convenience sampling approach approached 58 international, technology-savvy participants. Participants were offered a lunch voucher as an incentive. Participants were randomly assigned to one of the two conditions. To induce travel need-driven behaviour, participants were asked to imagine that they are selecting a place to visit. Participants were further instructed to use the website to book one attraction of their choice, while being informed that no charges would apply in the end. No time limitations were introduced. Two questions, delivered by push notifications, controlled the effect of the treatment for the TG. As the study aimed to explore tourists' experiences of using a presumably personalised website, only those respondents who accepted the data agreement were retained in the sample.

The study adopted three data collection methods. Similar to previous studies [22, 23], actual interactions with the website were recorded with the use of a Tobii Pro X260 eye-tracker. A post-experiment survey, based on a 5-point Likert UX scale [24] and a behavioural intention scale [25], was conducted. This allowed comparing the perceptions of the website's dependability, efficiency and perspicuity, as well as the overall experience of the website between the two groups. The data validity was ensured by an attention check question in the survey. Finally, semi-structured individual interviews were conducted to acquire insights into the participants' motivation and co-creation behaviour, including the participants' willingness to share personal data and the perceived value attributed to personalisation services. After the 3-stage validation procedure, the total $n=31$ cases, represented by $n=11$ male and $n=20$ female of 18 44 years old with a graduate $(n=27)$ and postgraduate $(n=4)$ degree, were retained. As a result, the TG and CG contained $n=15$ and $n=16$ cases, respectively.

The analysis consisted of the combination of qualitative and quantitative data. First, the visualised heatmaps and gaze plots were explored to identify differences in the 
respondents' interactions with the predefined areas of interests (AOI). Second, independent sample t-tests with $95 \%$ confidence interval were used to compare the differences between the gaze behaviour and UX, acquired from eye-tracking and survey. Third, thematic coding was applied to interpret the explanation of the experienced interactions. The findings were then triangulated.

\section{Findings}

This section reports the results of the data analysis collected from eye-tracking, survey and interviews. It first describes the understanding of personalisation technology for the TG and CG. Then it proceeds with exploring the differences in co-creation behaviour and acquired experiences, supplemented by the respondents' explanation.

\subsection{General Understanding of Personalisation Technology}

The participants from both, the TG and CG highlighted that they do not have an indepth understanding about personalisation technology itself: "I am looking for beautiful, huge presents and now my internet and computer is boomed with huge and cheesy things ... I don't know how it works I just know this happens". Twelve participants additionally highlighted that they would be interested in learning about the technical specifics of the personalisation process. Explicit information about personalisation is perceived as a valuable source for improving the understanding of the interactions with travel websites.

The information about the value of personalisation affects tourists' perception of the interactions. When asked about their general awareness about the purpose of data tracking, participants in the CG named third-parties ads, opportunity of a quick login to an account, and a more general purpose of "improved websites" as outcomes of personalisation. Information filtering was mentioned only by three out of 16 participants from the CG. After the interviewer named personalisation as one of the purposes of application of data, CG participants were often surprised:

"I never really thought about that before... that they can use Facebook for personalization, I mean I'm not sure if my Facebook reflects what kind of holiday want to go to but maybe it does. I just didn't think about it before...".

Participants assigned to the TG spent on average $\mathrm{M}=33.08 \mathrm{~s}, \mathrm{SD}=14.73 \mathrm{~s}$ for reading the treatment, which included the explanation of the purpose of data collection and value of data-driven personalisation. During the interviews, participants primarily indicated "sorting" and "rearranging" information as a key purpose of data collection. In other words, the information about the value of data-driven personalisation allows the participants to build awareness about the process of resource integration and the value it can deliver.

\subsection{Personalised Travel Information Website Dependability}

As expected, the website dependability is defined in relation to security of personal data application. Information about personalisation being applied, motivated participants to be more attentive to the data agreement page (Table 1). TG participants spent more 
time exploring the details of personal data usage in comparison to those in the $\mathrm{CG}$ $\left(\mathrm{n}_{\mathrm{TG}}=137, \mathrm{n}_{\mathrm{CG}}=133\right.$ fixations with $\mathrm{M}_{\mathrm{TG}}=44.2, \mathrm{M}_{\mathrm{CG}}=39.5 \mathrm{~s}$. of total duration of fixation).

Table 1. Tourist value co-creation behaviour and perceptions.

\begin{tabular}{|c|c|c|c|c|c|}
\hline & $\mathrm{M}_{\mathrm{TG}}$ & $\mathrm{SD}_{\mathrm{TG}}$ & $\mathrm{M}_{\mathrm{CG}}$ & $\mathrm{SD}_{\mathrm{CG}}$ & $\mathrm{M}_{\mathrm{TG}-\mathrm{CG}}$ \\
\hline \multicolumn{6}{|l|}{ Dependability (co-creation behaviour) } \\
\hline Fixation count/Data agreement & 138.53 & 56.47 & 124.86 & 53.87 & 13.67 \\
\hline Total fixation duration/Data agreement & 44.55 & 21.10 & 39.51 & 14.89 & 5.04 \\
\hline Fixation count/Attraction filter & 66.67 & 45.70 & 21.93 & 28.652 & $44.75 * * *$ \\
\hline Total fixation duration/Attraction filter & 29.45 & 17.06 & 8.35 & 5.86 & $21.09 * *$ \\
\hline \multicolumn{6}{|l|}{ Dependability (perceptions) } \\
\hline Predictability & 3.60 & 1.056 & 3.94 & 0,998 & -0.338 \\
\hline Supportiveness & 3.80 & 0.941 & 3.56 & 0.892 & 0.238 \\
\hline Security & 3.27 & 0.704 & 3.06 & 1.063 & 0.204 \\
\hline Correspondence to expectations & 3.53 & 0.743 & 3.50 & 1.095 & 0.033 \\
\hline \multicolumn{6}{|l|}{ Efficiency (co-creation behaviour) } \\
\hline Total fix. duration/Attractions list page & 72.26 & 36.36 & 37.51 & 16.85 & $34.75 * * *$ \\
\hline Fixation count/Attractions list page & 213.27 & 118.34 & 133.27 & 97.95 & $80 * *$ \\
\hline \multicolumn{6}{|l|}{ Efficiency (perceptions) } \\
\hline Speed of attraction selection & 3.40 & 1.298 & 4.31 & 1.014 & $-0.913 * *$ \\
\hline Efficiency of attraction selection & 3.80 & 1.082 & 3.69 & 1.138 & 0.113 \\
\hline Practicality of attraction selection & 4.20 & 0.941 & 3.69 & 1.195 & 0.513 \\
\hline Organisation of attraction selection & 4.53 & 0.640 & 4.44 & 0.512 & 0.096 \\
\hline \multicolumn{6}{|l|}{ Perspicuity (co-creation behaviour) } \\
\hline Total fixation duration/Attraction list & 38.01 & 18.91 & 31.39 & 15.82 & 6.613 \\
\hline Fixation count/Attraction list & 133.40 & 89.70 & 102.47 & 63.703 & 30.933 \\
\hline Time to $1^{\text {st }}$ click/Attraction list & 22.59 & 15.19 & 31.90 & 26.41 & -9.32 \\
\hline \multicolumn{6}{|l|}{ Perspicuity (perceptions) } \\
\hline Understanding & 4.47 & 0.640 & 4.44 & 0.814 & 0.029 \\
\hline Ease to learn & 4.80 & 0.414 & 4.75 & 0.577 & 0.050 \\
\hline Ease of use & 4.87 & 0.352 & 4.56 & 0.629 & 0.304 \\
\hline Clarity & 4.60 & 0.828 & 3.69 & 1.302 & $0.913 * *$ \\
\hline \multicolumn{6}{|l|}{ Overall experience (perceptions) } \\
\hline Enjoyability & 3.53 & 0.915 & 3.69 & 0.946 & -0.154 \\
\hline Goodness & 3.60 & 0.986 & 3.63 & 0.719 & -0.025 \\
\hline Likability & 3.87 & 0.915 & 3.63 & 1.025 & 0.242 \\
\hline Attractiveness & 3.60 & 1.056 & 3.25 & 1.000 & 0.350 \\
\hline User-friendliness & 3.87 & 0.834 & 3.88 & 0.885 & -0.008 \\
\hline \multicolumn{6}{|l|}{ Intention to Use (perceptions) } \\
\hline In future & 3.13 & 1.356 & 3.13 & 0.957 & 0.008 \\
\hline When required & 2.80 & 1.207 & 2.69 & 1.302 & 0.113 \\
\hline In the next trip & 3.27 & 1.335 & 3.06 & 1.289 & 0.204 \\
\hline Recommend to others & 3.37 & 1.187 & 3.19 & 1.276 & 0.279 \\
\hline
\end{tabular}


The heatmaps and gaze plots demonstrate different ways of consuming the information of the Data Agreement AOI. While in the TG content was read line by line (Fig. 1a), in the CG chaotic gaze patterns were prevalent with gaze movements going back and forth from the top left corner through the content to the "Agree to Share" button, and returning to the text (Fig. 1b).

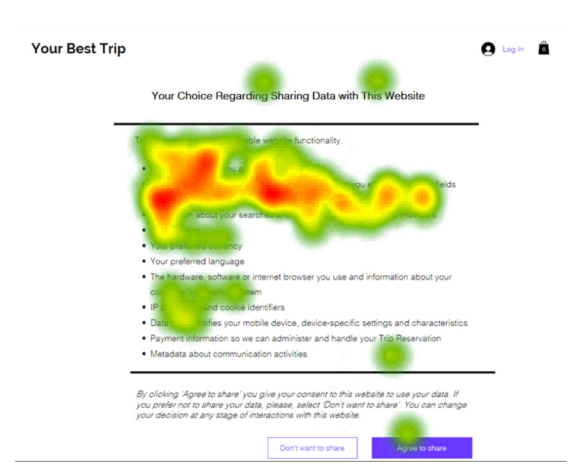

a. Treatment Group

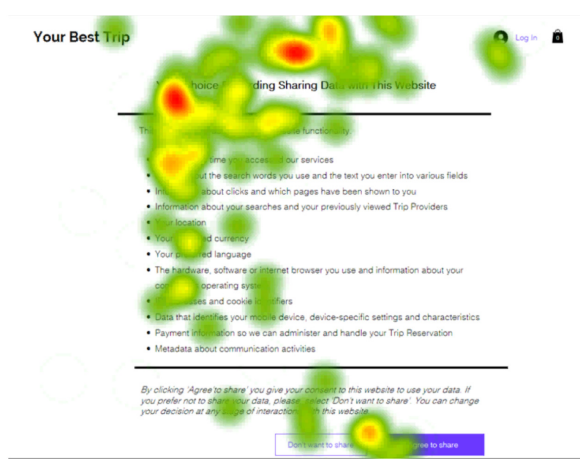

b. Control Group

Fig. 1. Attention to the personal data agreement

No significant difference between the TG and CG perceptions of dependability was detected (Table 1). The majority of the respondents acknowledged to be concerned with issues related to personal data protection. Participants reported that they do not feel secure about submitting personal details and logging-in to websites through the use of their social media profiles. However, 25 out of 31 participants indicated to submit their personal data to websites despite not having full trust in the service providers: "I am not sure if I trust it but I still risk it." No significant difference between the TG and $\mathrm{CG}$ in the attempts to minimise the perceived risks was identified. However, three out of $16 \mathrm{CG}$ participants and three out of $15 \mathrm{TG}$ participants explored the opportunity to change the data settings after giving consent. Interestingly, some participants shared the opinion that "it is their own responsibility now to manage the data", demonstrating an active value co-creation behaviour. Other participants offered a different perspective and indicated to be rather passive in regards to managing private data. They tend to comply with the proposed resource integration: "Everyone tracks data, everyone shares data - why care?".

Participants also highlighted that an increased awareness about personalisation builds "confidence" in sharing personal data. Similarly, the trustworthiness of brands and peer reviews seems to have a positive effect on the perception of personalisation services: "I guess the more I see it [information about personalisation being implemented] the more I will start to trust". An understanding of the process of personalisation motivates the participants to reassess the value of their own resources towards the value of personalisation. Several participants claimed that the risks of sharing 
personal data are low as they "have nothing to hide". While information about the value of personalisation does not eliminate privacy and security concerns, it motivates tourists to make more conscious decisions regarding the management of private data.

\subsection{Personalised Travel Information Website Efficiency}

The efficiency of the website was mainly associated with the time invested in the selection of relevant attractions. Contrary to the initial assumption, awareness about personalisation makes the selection of attractions both, more time- and attentionconsuming. In the TG, the counted number of fixations $\left(\mathrm{M}_{\mathrm{TG}^{-} \mathrm{CG}}=80^{* *}\right)$ and the total fixation duration $\left(\mathrm{M}_{\mathrm{TG}-\mathrm{CG}}=34.75^{* * *}\right)$ on the page with the list of attractions largely exceeded the recorded results in the CG. At the same time, the process of selecting attractions was slower for $\mathrm{TG}$ participants $\left(\mathrm{M}_{\mathrm{TG}-\mathrm{CG}}=0.913 * *\right)$. Therefore, information about personalisation can make the process of selection less efficient. Moreover, the TG participants revealed that explicit information about personalisation did not increase their expectations about the capability of personalisation to deliver the promised value proposition. Participants from both the TG and CG reported that the proposed attractions do not fully match their preferences. For example, price was named as a criterion that they do not expect to be personalised. Participants commonly agree on the fact that automated personalisation technology still needs to improve in terms of needs recognition accuracy: "I think it will serve me well because you know it will be based on my preference it will be based on my categories that I belong to, based on my preferences or taste or something like that so to it will be easier for me".

Filters were largely used as a tool to cope with possibly inaccurate context recognition: "A little personalisation is great for the beginning. You get that first impression and say "oh yeah this one". If you read further and you don't like it then you start playing with the filter". Participants from both groups further highlighted to explore the proposed list of services first and to later switch to select filtering options during the interactions with any personalised service. However, the visualised timeline demonstrated that TG participants largely started the page overview with exploring the filtering options. On the contrary, CG participants demonstrated an irregular gaze behaviour (Fig. 2). In the TG, the number of fixations on the Filter AOI was three times larger than that recorded in the $\mathrm{CG}\left(\mathrm{M}_{\mathrm{TG}}=66.67, \mathrm{M}_{\mathrm{CG}}=21.93, \mathrm{M}_{\mathrm{TG}}\right.$ $\left.\mathrm{CG}=44.75^{* * *}\right)$. There is even a larger difference between the $\mathrm{TG}$ and $\mathrm{CG}$ in terms of the total fixation duration $\left(\mathrm{M}_{\mathrm{TG}}=29.45 \mathrm{~s}, 66.67, \mathrm{M}_{\mathrm{CG}}=8.35, \mathrm{M}_{\mathrm{TG}-\mathrm{CG}}=21.09 * *\right)$. This indicates that the TG dedicated a significantly higher attention to the filtering criteria. 


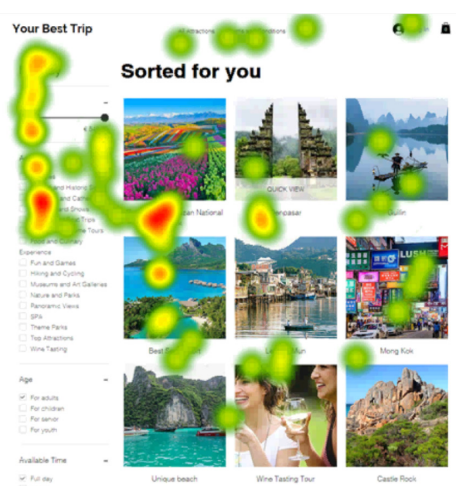

a. Treatment Group

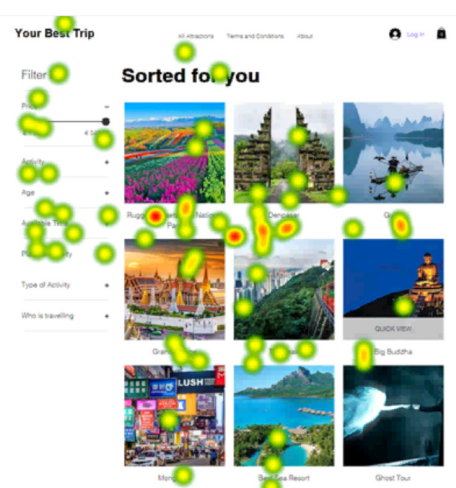

b. Control Group

Fig. 2. Attention to the selection of an attraction

Such differences in attention were explained by the preference to have an "overview" of attractions rather than having a narrow list of services. The expressions as "to check is everything is correct" or "make sure that the filters are right" were also used to justify the attempt to filter attractions: "I wanted to see how the destinations change... then if I'm not still satisfied with what I find then I use the filter and then I look again".

Surprisingly, the perceptions of the interactions with the Filter AOI between the TG and the CG did not vary. Nine out of 15 TG participants did not recognise the fact that they have accessed the filtering options. Moreover, four of them claimed to have not noticed the presence of filters at all, although the eye-tracking data demonstrated the contrary. Given that the validity of the eye-tracking data was ensured by the experimental settings, it seems that the TG participants may have interacted with the Filter AOI subconsciously.

\subsection{Personalised Travel Information Website Perspicuity}

The perceptions of perspicuity did not vary a lot between the two groups. Both the TG and CG perceived the proposed page with attractions as easy to use. Several TG participants named the presence of filters as the main reason of a clear and easy to use website. Additionally, the participants outlined that the opportunity to login with existing social media profiles made the website "easy" to use. However, automated personalisation was not mentioned as an important factor to make the website perspicuous.

The only difference between the two groups related to website clarity. The TG rated it higher than the $\mathrm{CT}\left(\mathrm{M}_{\mathrm{T}-\mathrm{C}}=0.913^{* *}\right)$. However, the $\mathrm{TG}$ explored the list of attractions for a longer period of time $\left(\mathrm{M}_{\mathrm{TG}}=38.01, \mathrm{M}_{\mathrm{CG}}=31.39, \mathrm{M}_{\mathrm{TG}-\mathrm{CG}}=6.613 * * *\right)$ and with more focus $\left(\mathrm{M}_{\mathrm{TG}}=133.40, \mathrm{M}_{\mathrm{CG}}=102.47, \mathrm{M}_{\mathrm{TG}-\mathrm{CG}}=30.93 * * *\right)$. Such behaviour might indicate confusion and complications in the decision-making as well as a high degree of interest. Self-reported data did however not provide any additional relevant insights to explain the observed behaviour. 


\subsection{Overall Experience and Use Intension}

The website received positive overall evaluation and average use intention scores from both groups. When reflecting on their experience, participants focused on their need satisfaction rather than on the website functionality with no significant differences between the groups. The website was often described as "interesting", "informative", "with beautiful attractions". When discussing the potential of personalisation, 28 out of 31 participants agreed that they would like to receive a personalised information. The participants also highlighted that they would prefer having two options: a personalised one and a full list of attractions. This further provides new evidence for the fact that tourists pay attention to need satisfaction and customer experience rather than to a specific technology [26].

\section{Discussion}

The findings demonstrate that the awareness about personalisation has a dual effect on tourist value co-creation behaviour. The information about personalisation being implemented raises tourist awareness about both, the potential value of personalisation and the possible threats which this might pose. Personalised travel information can be useful and supportive in the decision-making process. However, the results demonstrate that awareness about personalisation technology being implemented increases tourists' concerns about the accuracy of personalisation as well as the security and misuse of their personal data. In other words, the awareness about personalisation intensifies the personalisation-privacy paradox of the tourist co-creation behaviour [5].

The findings indicate a novel trend in which ensuring the delivery of the value of personalisation assumes priority over the establishment of control over the whole process of personalisation. Multiple studies demonstrate that the application of sensitive personal data by information systems makes them perceived as not dependable [10]. This motivates tourists to control information systems by establishing an alternative value co-creation strategy. Thus, tourists do not tend to control the outcome of personalised services [27]. Instead, they ensure that the planned resource integration is done according to their own needs. Failing to provide such value is likely to result in an interruption of interactions with the travel information website [28].

In the case of personalisation, control refers to modifying the applied data settings, the filtering criteria, the outcome, and the way how it is presented [10]. The results of the experiment demonstrate that tourists pay great attention to the personal data agreement page. However, they are reluctant to control their personal data. Instead, they let data-driven personalisation deliver the promised value. Tourists who are aware about personalisation being applied, simultaneously increase their engagement with the filtering options. Specifically, they invest time to ensure that the filtering criteria meet their requirements. However, there is no significant difference neither in the overall experience with the website, nor in the intention to use, although both groups did not rate them as advanced. In other words, awareness about personalisation being implemented cannot be defined as a moderator of a tourist's experience with personalised websites. 
The SDL explains such behaviour as value reinforcement [3,29]. Actors engage in resource integration for the purpose of value co-creation as they accept a value proposition. Value can be both co-created and co-destructed through resource integration. Value reinforcement therefore refers to additional resource incorporation in order to prevent any inappropriate resource integration with the accepted service. Value recovery behaviour serves a minimisation of consequences of an occurred resource misuse [30]. Tourist increasingly engage in citizenship behaviour of being tolerant to less satisfactory services and become more active in their attempts to support value cocreation [31]. They can be further motivated by voluntarily reconfiguring resource integration to ensure its appropriateness [32].

To be capable of contributing to value realisation, actors should have a congruent understanding of the resource integration process [33]. Value co-creation and codestruction represent a dynamic process, which can be affected by each actor. Understanding of value co-creation refers to the relevant interpretation of established processes of resource integration, purpose of engagement and the role of the actor in it. Being one of the key resources, information can serve as an operant resource to build a better understanding about value realisation potentialities by enabling actors to control and reconfigure resources [34]. When communicated explicitly, information about the purpose of personal data application helps with the tourists' understanding of the value co-creation process, enabling them to properly contribute to it.

Being value co-creators, tourists have the power to initiate the changes in the planned value co-creation process, and to further coordinate resource integration [35]. An understanding of the value co-creation process enables actors to select relevant resources and to develop the required competencies to engage in resource integration procedures [36,37]. Actors can dynamically build competencies to reconfigure resources in a way they perceive appropriate for the realisation of value [30]. The observed process of interactions, which included tourists' voluntary engagement in attractions' filtering process, expressed interest in receiving personalised information. At the same time, the unchanged overall experience and intention to use, reflect the attempt to ensure that the proposed value of a personalised list of attractions is realised. It seems that instead of taking over the control and modifying the outcome, tourists invested additional time in reconfiguring the applied process of filtering in order to receive the promised value. In other words, tourists demonstrated value reinforcement behaviour.

\section{Conclusion}

The study conducted an exploratory experiment. It searched for effects of tourist awareness about the value that personalisation offers on their experience with travel websites. The findings provide new evidence on the existence of a personalisationprivacy paradox. Tourists are willing to participate in resource integration to realise the value of personalisation while having concerns about the application of personal data. The study contributes to tourist co-creation behaviour, which has not been previously observed in the context of personalisation. Being motivated by the value proposition and the concerns of data misuse, tourists attempt to reinforce value realisation. 
This novel insight contributes to the domains of consumer behaviour, service management and UX design. It deepens the understanding of the tourist co-creation behaviour in the context of travel information and website personalisation. The study provides evidence on the idea of value reinforcement and actors' willingness to integrate additional resources, given a congruent understanding of the value co-creation process [3]. The paper further demonstrates the specifics of tourist behaviour with datadriven services, offering novel insights for service design in smart technological solutions.

The findings of the exploratory study have not provided enough evidence to explain all details of the observed behaviour. While the difference in the interactions with the website have been observed between the TG and CG, their perceptions of the experienced interactions seem to be similar. This might indicate that tourist behaviour of reconfiguring the filters is subconscious. Alternatively, this might be the limitation of self-reported data as people tend to forget details and report ideas that they believe to be expected. Alternatively, this might be a result of the small sample size. Future research is recommended to test the presence of subconscious behaviour and to develop an exhaustive explanation of the observed patterns. Furthermore, research exploring behavioural differences across target markets might contribute to improve personalisation strategies.

\section{References}

1. Buhali, D (2019) Technology in tourism-from information communication technologies to eTourism and smart tourism towards ambient intelligence tourism: a perspective article. Tour Rev (Association internationale d'experts scientifiques du tourisme) 75(1):267-272. https:// doi.org/10.1108/tr-06-2019-0258

2. Benson V, Saridakis G, Tennakoon H (2015) Information disclosure of social media users: Does control over personal information, user awareness and security notices matter? Inf Technol People 28(3):426-441

3. Echeverri P, Skålén P (2011) Co-creation and co-destruction: a practice-theory based study of interactive value formation. Market Theory 11(3):351-373

4. Mahroof K (2019) A human-centric perspective exploring the readiness towards smart warehousing: the case of a large retail distribution warehouse. Int J Inf Manage 45:176-190

5. TusTussyadiah I, Li S, Miller G (2019) Privacy protection in tourism: Where we are and where we should be heading for. In: Information and communication technologies in tourism, pp 278-290. Springer, Heidelberg

6. Fink J, Kobsa A, Nill A (1998) Adaptable and adaptive information provision for all users, including disabled and elderly people. New Rev Hypermedia Multimedia 4(1):163-188

7. Sigala M (2012) Mass customisation models for travel and tourism information e-services

8. Volchek K, Law R, Buhalis D, Song H (2020) Exploring ways to improve personalisation: the influence of tourist context on service perception. E-review Tour Res 17(5):737-752

9. Morosan C, Defranco A (2016) Modeling guests' intentions to use mobile apps in hotels: the roles of personalization, privacy, and involvement. Int J Contemp Hosp Manage 28 (9):1968-1991

10. Volchek K, Law R, Buhalis D, Song H (2019) The good, the bad, and the ugly: tourist perceptions on interactions with personalised content. e-Review of Tour Res 16(2-3):62-72 (2019) 
11. Ricci F (2020) Recommender systems in tourism. In: Xiang Z, Fuchs M, Gretzel U, Höpken W (eds) Handbook of e-Tourism, pp 1-18. Springer, Cham

12. Magnini V (2017) Designing tourism services in an era of information overload. In: Fesenmaier DR, Xiang Z (eds) Design science in tourism: foundations of destination management, pp 161-172. Springer, Cham

13. Choi IY, Ryu YU, Kim JK (2019) A recommender system based on personal constraints for smart tourism city. Asia Pac J Tour Res 1(14) (2019). https://doi.org/10.1080/10941665. 2019.1592765

14. Vargo SL, Lusch RF, Brodie RJ, Storbacka K (2014) Inversions of service-dominant logic. Market Theory 14(3):239-248 (2014). https://doi.org/10.1177/1470593114534339

15. McColl-Kennedy JR, Cheung L, Ferrier E (2015) Co-creating service experience practices. J Serv Manage 26(2):249-275

16. Makkonen H, Olkkonen $\mathrm{R}$ (2017) Interactive value formation in interorganizational relationships: dynamic interchange between value co-creation, no-creation, and codestruction. Market Theory 17(4):517-535. https://doi.org/10.1177/1470593117699661

17. Wise N, Heidari H (2019) Developing smart tourism destinations with the Internet of Things. In: Sigala M, Rahimi R, Thelwall M (eds) Big data and innovation in tourism, travel, and hospitality: managerial approaches, techniques, and applications, pp 21-29. Springer, Singapore

18. Neuhofer B, Buhalis D, Ladkin A (2015) Smart technologies for personalized experiences: a case study in the hospitality domain. lectron. Markets 25(3):243-254

19. Voigt P, Von dem Bussche A (2017) The EU general data protection regulation (GDPR). A practical guide, 1st edn. Springer, Cham

20. Salonen V, Karjaluoto H (2016) Web personalization: the state of the art and future avenues for research and practice. Telematics Inform 33(4):1088-1104 . https://doi.org/10.1016/j. tele.2016.03.004

21. Powers E (2017) My news feed is filtered? Digit J 5(10):1315-1335. https://doi.org/10.1080/ 21670811.2017.1286943

22. Rainoldi M, Neuhofer B, Jooss M (2018) Mobile eyetracking of museum learning experiences. In: Information and communication technologies in tourism, pp 473-485. Springer, Heidelberg

23. Hopf J, Scholl M, Neuhofer B, Egger R (2020) Exploring the impact of multisensory VR on travel recommendation: a presence perspective. In: Information and communication technologies in tourism, pp 169-180. Springer, Heidelberg

24. Schrepp M, Hinderks A, Thomaschewski J (2017) Construction of a benchmark for the user experience questionnaire (UEQ). IJIMAI 4(4):40-44

25. Venkatesh V, Thong JYL, Xu X (2016) Unified theory of acceptance and use of technology: a synthesis and the road ahead. In: Association for information systems, pp 328-376 (2016)

26. Cabiddu F, Lui T-W, Piccoli G (2013) Managing value co-creation in the tourism industry. Ann Tour Res 42:86-107

27. Guo L, Lotz SL, Tang C, Gruen TW: The role of perceived control in customer value cocreation and service recovery evaluation. J Serv Res 19(1), 39-56 (2016)

28. Lee CH, Cranage DA (2011) Personalisation-privacy paradox: the effects of personalisation and privacy assurance on customer responses to travel Web sites. Tour Manage 32(5):987994

29. Camilleri J, Neuhofer B (2017) Value co-creation and co-destruction in the Airbnb sharing economy. Int J Contemp Hosp Manage 29(9):2322-2340. https://doi.org/10.1108/IJCHM09-2016-0492 
30. Koskela-Huotari K, Edvardsson B, Jonas JM, Sörhammar D, Witell L (2016) Innovation in service ecosystems - breaking, making, and maintaining institutionalized rules of resource integration. J Bus Res 69(8):2964-2971 (2016). https://doi.org/10.1016/j.jbusres.2016.02. 029

31. Assiouras I, Skourtis G, Giannopoulos A, Buhalis D, Koniordos M (2019) Value co-creation and customer citizenship behavior. Ann Tour Res 78:102742. https://doi.org/10.1016/j. annals.2019.102742

32. Storbacka K (2019) Actor engagement, value creation and market innovation. Ind Mark Manage 80:4 (2019). https://doi.org/10.1016/j.indmarman.2019.04.007

33. Waseem D, Biggemann S, Garry T (2018) Value co-creation: the role of actor competence. Ind Mark Manage 70:5-12. https://doi.org/10.1016/j.indmarman.2017.07.005

34. Johansson AE, Raddats C, Witell L (2019) The role of customer knowledge development for incremental and radical service innovation in servitized manufacturers. J Bus Res 98:328338

35. Akaka MA, Vargo SL, Wieland H (2017) Extending the context of innovation: the cocreation and institutionalization of technology and markets. In: Innovating in practice, pp 43-57. Springer, Heidelberg

36. Lusch RF, Nambisan S (2015) Service innovation: a service-dominant logic perspective. MIS Q 39(1):155-176

37. Vargo SL, Lusch RF (2013) Institutions and axioms: an extension and update of servicedominant logic. J Acad Mark Sci 44(1):5-23

Open Access This chapter is licensed under the terms of the Creative Commons Attribution 4.0 International License (http://creativecommons.org/licenses/by/4.0/), which permits use, sharing, adaptation, distribution and reproduction in any medium or format, as long as you give appropriate credit to the original author(s) and the source, provide a link to the Creative Commons license and indicate if changes were made.

The images or other third party material in this chapter are included in the chapter's Creative Commons license, unless indicated otherwise in a credit line to the material. If material is not included in the chapter's Creative Commons license and your intended use is not permitted by statutory regulation or exceeds the permitted use, you will need to obtain permission directly from the copyright holder.

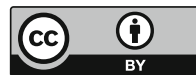

